\title{
Role of the Alfalfa mosaic virus Movement Protein and Coat Protein in Virus Transport
}

\author{
Jesús A. Sánchez-Navarro and John F. Bol \\ Institute of Molecular Plant Sciences, Gorlaeus Laboratories, Leiden University, P.O. Box 9502, 2300 RA \\ Leiden, The Netherlands \\ Submitted 26 February 2001; Accepted 1 May 2001.
}

\begin{abstract}
The movement protein (MP) and coat protein (CP) encoded by Alfalfa mosaic virus (AMV) RNA 3 are both required for virus transport. RNA 3 vectors that expressed nonfused green fluorescent protein (GFP), MP:GPF fusions, or GFP:CP fusions were used to study the functioning of mutant MP and $\mathrm{CP}$ in protoplasts and plants. Cterminal deletions of up to 21 amino acids did not interfere with the function of the $\mathrm{CP}$ in cell-to-cell movement, although some of these mutations interfered with virion assembly. Deletion of the N-terminal 11 or C-terminal 45 amino acids did not interfere with the ability of MP to assemble into tubular structures on the protoplast surface. Additionally, N- or C-terminal deletions disrupted tubule formation. A GFP:CP fusion was targeted specifically into tubules consisting of a wild-type MP. All MP deletion mutants that showed cell-to-cell and systemic movement in plants were able to form tubular structures on the surface of protoplasts. Brome mosaic virus (BMV) MP did not support AMV transport. When the C-terminal 48 amino acids were replaced by the $C$-terminal 44 amino acids of the AMV MP, however, the BMV/AMV chimeric protein permitted wild-type levels of AMV transport. Apparently, the $\mathrm{C}$ terminus of the AMV MP, although dispensable for cell-to-cell movement, confers specificity to the transport process.
\end{abstract}

Infection of plants by viruses requires cell-to-cell movement of the virus in the primary infected leaf and subsequent systemic movement through the vascular system. At least two different mechanisms of cell-to-cell movement are known (Carrington et al. 1996; Lazarowitz and Beachy 1999; McLean et al. 1997). One is exemplified by the Tobacco mosaic virus (TMV, genus Tobamovirus) and involves transport of unencapsidated viral RNA and a movement protein (MP) through modified plasmodesmata (Citovsky et al. 1992; Heinlein et al. 1995; McLean et al. 1995; Wolf et al. 1989). The second mechanism is represented by the Cowpea mosaic virus (CPMV, genus Comovirus) (Van Lent et al. 1990) and requires a MP and coat protein $(\mathrm{CP})$ for cell-to-cell movement. The CPMV MP forms tubular structures that traverse the cell wall through modified plasmodesmata, and these tubules mediate transport of virions from the infected cell to neighboring healthy cells. Tubule-guided transport of virus

Corresponding author: J. F. Bol; Telephone: +31 71 5274749; Fax: +31 71527 4469; E-mail: j.bol@ chem.leidenuniv.nl particles has been described for several other plant viruses belonging to the genera Badnavirus (Cheng et al. 1998), Caulimovirus (Linstead et al. 1988), Nepovirus (Ritzenthaler et al. 1995), and Tospovirus (Storms et al. 1995), and the family Geminiviridae (Kim and Lee 1992).

Alfalfa mosaic virus (AMV) is the type species of the genus Alfamovirus in the family Bromoviridae. Currently, the mechanism of AMV movement is not clear. The AMV genome consists of three plus-stranded RNAs. Monocistronic RNAs 1 and 2 encode the nonstructural $\mathrm{P} 1$ and $\mathrm{P} 2$ polymerase proteins. The dicistronic RNA 3 encodes the MP and CP, and the $\mathrm{CP}$ is translated from a subgenomic messenger RNA 4. Within the family Bromoviridae, a mixture of the three genomic RNAs of viruses from the genera Alfamovirus and Ilarvirus is not infectious unless a few molecules of $\mathrm{CP}$ are bound to the 3' end of each genomic RNA (Bol 1999). On the surface of AMV-infected protoplasts, the MP forms tubular structures, which appear to be filled with virus particles (Kasteel et al. 1997). Transient expression of AMV MP in protoplasts is sufficient for tubule formation (Zheng et al. 1997). These observations are in line with a mechanism for tubule-guided cell-tocell transport of AMV virions. Virion-containing tubules, however, could not be detected in infected Nicotiana benthamiana plants. Similar to the TMV MP (Citovski et al. 1992), the AMV MP has nonspecific RNA binding properties (Schoumacher et al. 1994) and is able to induce a limited increase of the size exclusion limit of plasmodesmata (Poirson et al. 1993). Several AMV CP mutants have been generated that accumulate in infected protoplasts but not in plants, whereas other $\mathrm{CP}$ mutants accumulate in plants at reduced levels but do not produce detectable virus particles (Tenllado and Bol 2000; Van der Vossen et al. 1994). This indicates that AMV CP is involved in cell-to-cell movement, without the requirement for the formation of stable virus particles.

Mutational analysis was used to characterize different domains in the AMV MP. The region between amino acids 21 and 34 plays a role in targeting the MP to the cell wall (Berna 1995; Erny et al. 1992), whereas the region located between residues 36 and 81 was identified as the nonspecific RNA binding domain (Schoumacher et al. 1994). The N-terminal 77 amino acids of the AMV MP were not required to increase the size exclusion limit of the plasmodesmata (Poirson et al. 1993). Large deletions located at the $\mathrm{N}$ terminus (amino acids 1 to 77), central region (amino acids 84 to 142), or C terminus (amino acids 226 to 300) affected tubule formation of the MP, which was expressed transiently in protoplasts (Zheng et al. 1997). Amino acids 87 to 100 are located within the conserved 
motif of the "30K" superfamily of MPs (Melcher 2000) and are predicted to be a transmembrane domain (SánchezNavarro et al. 1997). Huang and Zhang (1999) used subcellular fractionation and immunoblotting studies to demonstrate that AMV MP behaves as an integral membrane protein of the endoplasmic reticulum.

Like AMV, other members of the Bromoviridae family induce tubule formation by the MP, including Tobacco streak virus (TSV) (Martelli and Russo 1985), Olive latent virus 2 (OLV-2) (Grieco et al. 1999), Cucumber mosaic virus (CMV) (Canto and Palukaitis 1999), and Brome mosaic virus (BMV) (Kasteel et al. 1997). Phylogenetically, the AMV MP and CP are closely related to the MPs and CPs of ilarviruses and more distantly related to the corresponding proteins of other members of the Bromoviridae family (Sánchez-Navarro and Pallas 1997). Previously, we showed that the MP and CP of the ilarvirus Prunus necrotic ringspot virus (PNRSV) could support AMV cell-to-cell movement (Aparicio et al. 2001; SánchezNavarro et al. 1997). In the present work, we used different AMV RNA 3 vectors that express the green fluorescent protein (GFP) as tools to further study the role of the AMV MP and $\mathrm{CP}$ in cell-to-cell movement. In addition, we investigated the ability of the BMV MP and AMV/BMV MP chimeras to support the local and systemic movement of AMV.

\section{RESULTS}

\section{Intracellular distribution of the AMV MP and CP in infected tobacco leaves and protoplasts.}

Plasmid pAL3 contains a DNA copy of the AMV RNA 3 adjacent to a $\mathrm{T}_{7}$ promoter. Recently, we modified this plasmid to create pGFP/MP/CP (Sánchez-Navarro et al. 2001). The pGFP/MP/CP plasmid contains the GFP gene inserted adjacent to the $5^{\prime}$ leader sequence and a duplicated subgenomic promoter (sgp) sequence (Fig. 1, upper panel). After inoculation of the RNA transcripts of $\mathrm{pGFP} / \mathrm{MP} / \mathrm{CP}$ on tobacco plants transformed with the AMV P1 and P2 genes (P12 plants), the modified RNA 3 accumulates at wild-type levels in the inoculated leaves but is unable to move systemically (SánchezNavarro et al. 2001). The accumulation of GFP expressed by this RNA vector in the cytoplasm of epidermal cells (Fig. 1a1) or mesophyll cells (Fig. 1a2) of infected P12 plants resembles that of GFP expressed transiently by agroinfiltration of healthy P12 leaves (Fig. 1b1 and b2). In infected P12 protoplasts, GFP accumulated in the cytoplasm and occasionally in the nucleus (Fig. 1a3). To investigate the subcellular location of the MP, plasmid pGFP/MP/CP was modified into pMP:GFP/MP/CP by fusing a duplicated copy of the MP gene in-frame to the $5^{\prime}$ end of the GFP gene. The MP:GFP expressed from $\mathrm{pMP}: \mathrm{GFP} / \mathrm{MP} / \mathrm{CP}$ accumulated in the cell wall of infected epidermal and mesophyll cells in punctate structures (Fig. 1c1 and $\mathrm{c} 2$ ). In infected P12 protoplasts, the MP:GFP fusion protein accumulated in tubular structures protruding from the protoplast surface (Fig. 1c3). We also fused the MP gene in-frame to the $3^{\prime}$ end of the GFP gene in plasmid pGFP:MP/MP/CP. The GFP:MP fusion protein expressed from this plasmid accumulated in the cell wall and cytoplasm of infected epidermal and mesophyll cells (Fig. 1d1 and d2). In infected P12 protoplasts, however, the GFP:MP fusion protein did not form tubular structures but instead accumulated in punctate structures in the plasma membrane and in larger aggregates connected with this membrane (Fig. 1d3). Apparently, the fusion of GFP to the N terminus of the MP interfered with the assembly of tubules, consisting of the fusion protein or of mixtures of fusion protein and wild-type MP. Note that the GFP:MP and MP:GFP fusion proteins are not functional in transport, and cell-to-cell movement of the corresponding RNA vectors is dependent upon the encoded nonfused MP (Sánchez-Navarro et al. 2001; our unpublished results). To investigate the subcellular location of the $\mathrm{CP}$, a duplicated copy of the CP gene was fused in-frame to the $5^{\prime}$ end of the GFP gene in plasmid pCP:GFP/MP/CP. The $\mathrm{CP}$ :GFP fusion protein expressed from this plasmid accumulated in the cytoplasm and in or near the cell walls of infected epidermal and mesophyll cells of P12 plants (Fig. 1e1 and e2). In infected P12 protoplasts, the CP:GFP fusion protein was mainly in the cytoplasm (Fig. 1e3). We also fused a copy of the CP gene in-frame to the $3^{\prime}$ end of the GFP gene in pGFP/MP/CP to create plasmid GFP:CP/MP/CP. A significant proportion of the GFP:CP fusion protein expressed by the RNA transcript of this plasmid accumulated in punctate structures in the cell wall (Fig. 1f1) and into putative tubular structures that appeared to traverse the cell wall from one infected cell to another (Fig. 1f1 and f2). A fraction of the GFP:CP fusion protein accumulated in tubular structures protruding from infected P12 protoplasts as well as in punctate structures in the protoplast membrane (Fig. 1f3). Because the accumulation of the GFP:CP fusion protein in tubular structures was dependent upon the coexpression of a functional MP (result not shown), the fusion protein apparently accumulated in tubules consisting of the MP. Moreover, note that the CP:GFP and GFP:CP fusion proteins are not functional in cell-to-cell movement or virion formation, and transport of the vector RNAs encoding these proteins is dependent upon the encoded nonfused CP (SánchezNavarro et al. 2001; our unpublished results).

\section{C-terminal sequences of the AMV CP are dispensable for cell-to-cell movement.}

The AMV CP is 220 amino acids long. Previously, we have shown that a C-terminal deletion of this protein of seven amino

Fig. 1. Detection of green fluorescence in P12 protoplasts and plants after inoculation with Alfalfa mosaic virus (AMV)-green fluorescent protein (GFP) chimeras. P12 protoplasts and plants were inoculated with RNA transcripts from plasmids expressing a nonfused GFP (pGFP/MP/CP; a1-a3) or the fusion proteins movement protein (MP):green fluorescent protein (GFP) (pMP:GFP/MP/CP; c1-c3), GFP:MP (pGFP:MP/MP/CP; d1-d3), CP:GFP (pCP:GFP/MP/CP; e1-e3), and GFP:CP (pGFP:CP/MP/CP; f1-f3). Fluorescence was monitored with a confocal laser scanning microscope 16 h after inoculation of protoplasts (lane 3 ) or 3 days after inoculation of plants (lanes 1 and 2). Fluorescence observed in infected epidermal cells or mesophyll cells is shown in lanes 1 and 2, respectively. b1 and b2, Fluorescent signal obtained when nonfused GFP was expressed transiently from a T-DNA vector 3 days after agroinfiltration. Schematic representations of AMV-GFP chimeric RNAs are shown on the left. Reading frames encoding the GFP, MP, and coat protein $(\mathrm{CP})$ are represented by green, red, and yellow boxes, respectively. Arrows with solid and broken lines indicate fluorescent spots and tubular structures, respectively. Bar $=10 \mu \mathrm{m}$. 
P12 plants

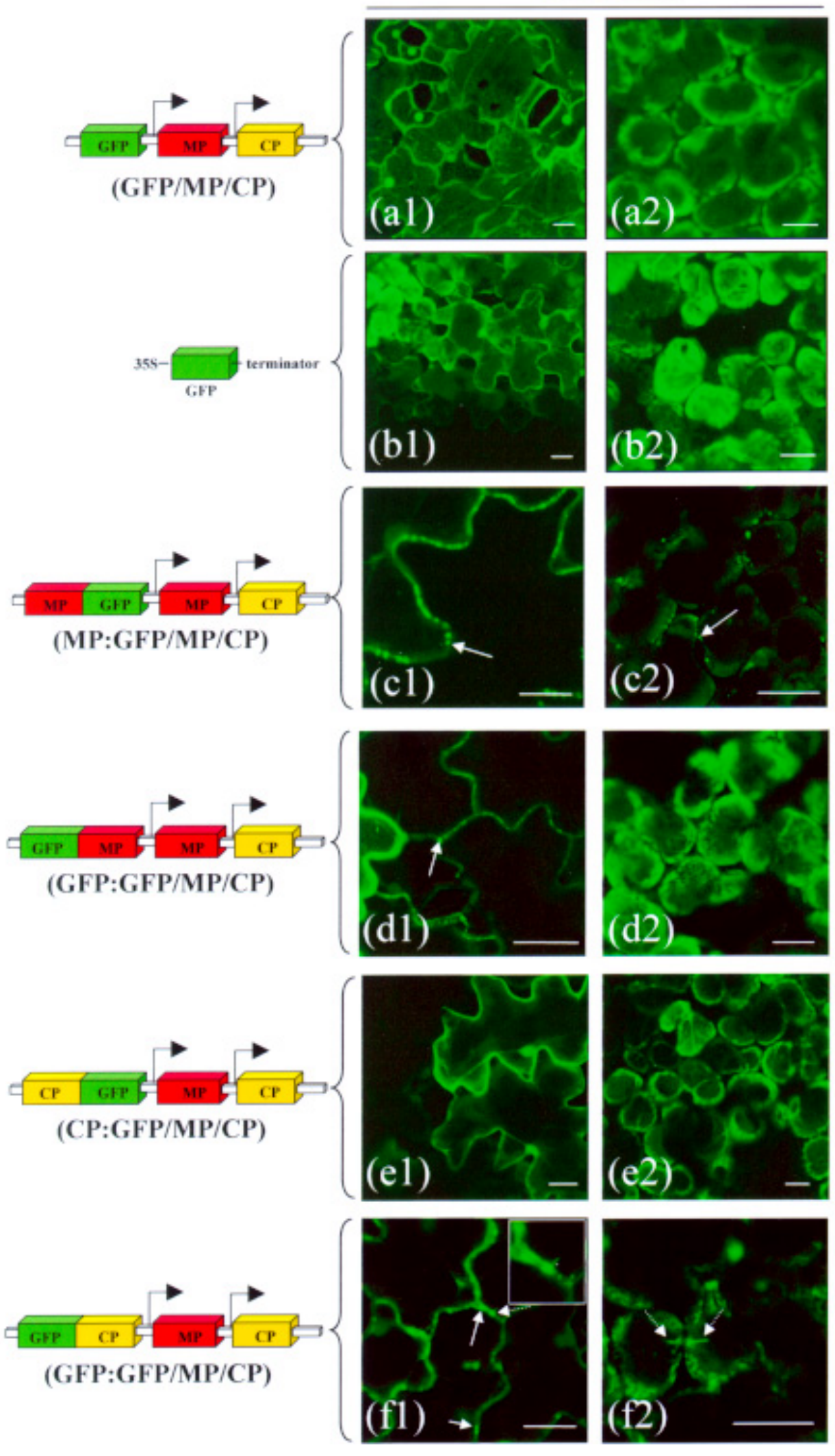

P12 protoplasts
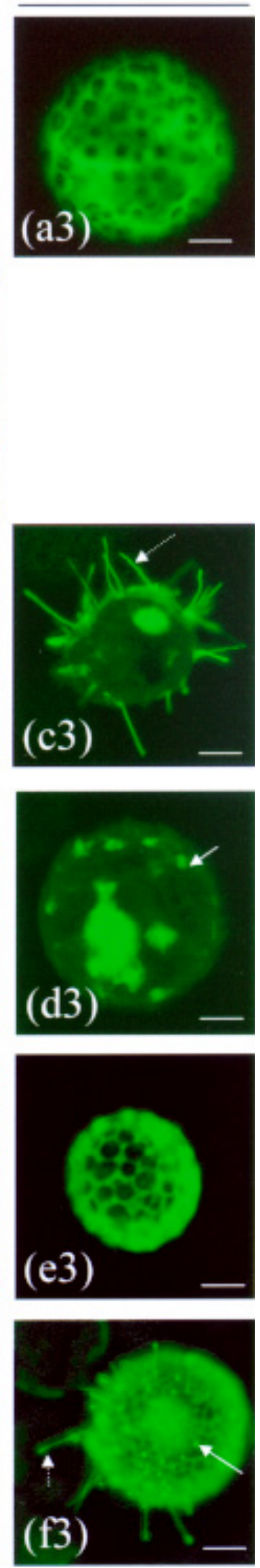
acids (mutant CP-N213) had no significant effect on the encapsidation or accumulation of the virus in P12 plants or protoplasts, whereas deletions of 14 (mutant CP-N206) or 21 amino acids (mutant CP-N199) interfered with encapsidation and reduced the accumulation of the viral RNAs in P12 plants and protoplasts to levels that were 1 to $5 \%$ of the wild type (Tenllado and Bol 2000; Van der Vossen et al. 1994). The CP gene in plasmid pGFP/MP/CP was replaced by the three mutant CP genes, and transcripts of these plasmids were used to infect P12 plants. At 3 days postinfection (dpi), the transcripts with the wild-type and CP-N213 genes induced infection foci of similar sizes and green fluorescence (Fig. 2a and b). The transcript with the CP-N199 gene induced infection foci of wild-type size, but these were barely visible as a result of the strongly reduced fluorescence (Fig. 2d). The transcript with the CP-N206 gene induced foci of reduced size and fluorescence (Fig. 2c). Because the infections with the three CP mutants were not restricted to single cells, the results clearly indicate that the C-terminally truncated CPs were functional in cell-to-cell movement. The reduction in the accumulation of RNAs of mutants CP-N206 and CP-N199 in inoculated leaves (Tenllado and Bol 2000) is probably the result of reduced accumulation of viral RNA per infected cell.

\section{Domains of the AMV and BMV MP required for tubule formation in protoplasts.}

Domains of the AMV MP with a role in tubule formation were analyzed by engineering deletions in the MP sequence of plasmid pMP:GFP/CP (Fig. 3). In contrast to pGFP/MP/CP, this plasmid does not express wild-type MP, which could influence the results. Northern blot analysis showed that transcripts of all pMP:GFP/CP derivatives with modified MP sequences accumulated at wild-type levels in protoplasts (data not shown). Tubule formation induced by the transcript that encodes the 300 amino acids wild-type MP fused to GFP is shown in Figure 3a. The tubules were observed on the surface of approximately $75 \%$ of the protoplasts that were infected, as judged by the accumulation of green fluorescence. The other $25 \%$ of the infected protoplasts showed fluorescence of punctate structures only at the plasma membrane. These results are similar to those obtained with protoplasts infected with transcripts of pMP:GFP/MP/CP. Thus, the wild-type MP expressed by transcripts of this plasmid did not affect the results (Fig. 1c3).

The results of a deletion analysis of the AMV MP sequence is summarized in Table 1. MP mutants with C-terminal deletions of 26 (mutant AMV1-274), 33 (AMV1-267), 40 (AMV1-260), and 45 amino acids (AMV1-255) induced the formation of fluorescent tubules on 60 to $80 \%$ of the infected protoplasts (Table 1). A MP mutant with a C-terminal deletion of 53 amino acids (AMV1-247), however, induced tubule formation only in $0.5 \%$ of the infected protoplasts, whereas no tubule formation was detectable when the C-terminal 59 amino acids (AMV1-241) were deleted. Mutants AMV1-247 and AMV1-241 predominantly induced the formation of fluorescent punctate structures at the plasma membrane (Fig. 3b). These mutant MP:GFP fusions also were used to replace the GFP gene in plasmid pGFP/MP/CP. Transcripts of the resulting plasmids pA1-247:GFP/MP/CP and pA1-241:GFP/MP/CP coexpressed the mutant MP:GFP fusion proteins and the wildtype MP. This coexpression resulted in the incorporation of the A1-247:GFP fusion protein into tubular structures on $28 \%$ of the infected protoplasts but did not result in the incorporation of the A1-241:GFP fusion protein into tubules (Table 1). Apparently, the A1-247:GFP fusion protein is able to interact with wild-type MP (or possible host proteins in tubular structures), and this interaction is lost in the A1-241:GFP fusion protein.

To delineate the minimal sequences of AMV MP required for tubule formation, three $\mathrm{N}$-terminal deletions were introduced into mutant AMV1-255. Deletion of the N-terminal 11 amino acids (AMV12-255) reduced the percentage of infected protoplasts that showed tubule formation from 60 to $9.3 \%$ (Fig. 3c and Table 1). Deletion of the N-terminal 19 (AMV20255) or 25 amino acids (AMV26-255) abolished tubule formation (Table 1). This indicates that the MP sequence of amino acids 12 to 255 was sufficient for tubule formation, whereas elements in the $\mathrm{N}$ - and $\mathrm{C}$-terminal flanking sequences enhanced the efficiency of tubule formation. Analysis of different sections of single protoplasts by confocal laser scanning microscopy revealed that AMV20-255 accumulates in intracellular aggregates and punctates structures at the protoplast surface (Fig. 3d), whereas mutant AMV26-255 accumulates predominantly in intracellular aggregates (Fig. 3f).

The differences in the results obtained with mutants AMV1-255 (60\% tubule formation) and AMV1-247 (0.5\% tubule formation) pointed to a critical role of amino acids 248 to 256 in tubule formation. Deletion of these nine amino acids in mutant AMV 248 -256, however, did not abolish tubule formation but resulted in a percentage of infected protoplasts with tubules of $26.6 \%$ (Table 1). Extension of the internal deletion of mutant AMV $\Delta 248-256$ to amino acids 242 to 256 (mutant AMV $242-256$ ) resulted in a drop of the percentage of infected protoplasts that showed tubule formation to $4.6 \%$ (Table 1). Apparently, the defect in tubule formation of mutant AMV1-247 can be restored by extending the sequence of amino acids 1 to 247 with 248 to 255 (mutant AMV1-255) or amino acids 257 to 300 (mutant AMV $\Delta 248-256)$. Extension of amino acids 1 to 241 with 257 to 300 (mutant AMV $\Delta 242-256$ ) also yielded a reduced level of tubule formation (Table 1).

In plasmid pB1-303:GFP/CP, the AMV MP sequence of plasmid pMP:GFP/CP was replaced by a sequence encoding the 303 amino acids BMV MP. Green fluorescent tubules were observed on $4 \%$ of the P12 protoplasts infected with transcripts of pB1-303:GFP/CP (Fig. 3e and Table 1). Deletion of the C-terminal 43 amino acids of the BMV MP (mutant BMV1-260) did not affect tubule formation, but deletion of the C-terminal 48 amino acids (mutant BMV1-255) increased the percentage of infected protoplasts with tubules to $12 \%$. Deletion of the C-terminal 55 amino acids (mutant BMV1248) or larger (BMV1-240) deletions abolished tubule formation by the BMV MP. Additionally, the MP of mutant BMV1248 was not incorporated into tubules when coexpressed with wild-type AMV MP from transcripts of plasmid pB1248:GFP/MP/CP (Table 1). The extension of mutant AMV1247 with the C-terminal 44 amino acids of AMV MP to give mutant AMV $\Delta 248-256$ resulted in a strong enhancement of tubule formation. The extension of mutants BMV1-255 and BMV1-248 with the C-terminal 44 amino acids of AMV MP (mutants B255:A44 and B248:A44), however, had no effect on tubule formation (Table 1). 


\section{Domains of the AMV and BMV MP required for cell-to-cell movement.}

The wild-type AMV MP gene in plasmid pGFP/MP/CP (Fig. 4) was replaced by several mutant AMV or BMV MP genes, and the expression of GFP by transcripts of these plasmids was used to monitor cell-to-cell transport in the inoculated leaves of P12 plants. C-terminal deletions of the AMV and BMV MP were made by engineering stop codons in the corresponding reading frames. Figure $4 \mathrm{a}$ shows one of the infection foci induced at $3 \mathrm{dpi}$ by the transcript with the wildtype AMV MP (Table 1). Deletion of the C-terminal 45 amino acids of the MP (AMV1-255) resulted in the induction of foci at 3 dpi that were significantly smaller (Fig. $4 \mathrm{~b}$ and Table 1). Unexpectedly, the deletion of only the C-terminal 26 amino acids (AMV1-274) resulted in an infection that was limited to single cells (Table 1). Additionally, a C-terminal deletion of 53 amino acids (AMV1-247) caused a complete block of cellto-cell movement (Fig. 4g and Table 1). The introduction of $\mathrm{N}$-terminal deletions of 11,19 , or 25 amino acids in mutant AMV1-255 (mutants AMV12-255, AMV20-255, AMV26255) abolished the cell-to-cell movement of this mutant (Table 1). Internal deletions of nine amino acids in mutant AMV $\Delta 248-256$ or 15 amino acids in mutant AMV $\Delta 242-256$ yielded mutants that produced infection foci of wild-type size (Fig. 4c and d and Table 1). These two mutants correspond to mutants AMV1-247 and AMV1-241, each extended with the C-terminal 44 amino acids of the AMV MP. The enhancement of cell-to-cell movement by this 44 amino acids sequence is specific because extension of AMV1-247 with a C-terminal GFP sequence of 44 amino acids (mutant A247:G44) did not permit cell-to-cell movement. Moreover, the C-terminal extension of AMV1-255 with this 44 amino acids GFP sequence (mutant A255:G44) abolished cell-to-cell movement (Table 1).

Replacement of the AMV MP gene in $\mathrm{pGFP} / \mathrm{MP} / \mathrm{CP}$ by the wild-type BMV MP gene resulted in plasmid pGFP/B1303/CP. Transcripts of this plasmid induced infection of single cells but no cell-to-cell movement was observed (Table 1). A low level of cell-to-cell movement was observed at $3 \mathrm{dpi}$, with a mutant in which the C-terminal 48 amino acids of the BMV MP were deleted (mutant BMV1-255) (Fig. 4e and Table 1). Deletion of the 55 C-terminal amino acids (BMV1-248) abolished cell-to-cell movement. Extension of the truncated BMV MP of mutant BMV1-255 with the C-terminal 44 amino acids of the AMV MP (mutant B255:A44) increased cell-to-cell movement by this mutant to a level similar to that obtained with wild-type AMV MP (Fig. 4f and Table 1). A similar extension to mutant BMV1-248 (B248:A44) did not enable this mutant BMV MP to support cell-to-cell transport (Fig. 4h and Table 1).

\section{Domains of AMV and BMV MP required for systemic movement.}

Because the RNA 3 derivative transcribed from pGFP/MP/CP does not move systemically in P12 tobacco (Sánchez-Navarro et al. 2001), the MP gene in wild-type RNA 3 was replaced by various mutant MP gene constructs to analyze the role of MP in systemic movement. P12 plants were inoculated with mutant RNA 3 transcripts, and RNA and protein were extracted from the inoculated leaves at $5 \mathrm{dpi}$ and from the noninoculated upper leaves at 12 dpi. RNA was analyzed by Northern blot hybridization with probes correspond- ing to the AMV CP gene (Fig. 5a and c) or the BMV MP gene (Fig. 5b). Protein was analyzed on Western blots with an antiserum raised to a synthetic peptide corresponding to the C-terminal 40 amino acids of AMV MP (Fig. 5d and e). As expected, no systemic infection was detectable for the mutants shown to be defective in cell-to-cell movement with derivatives of plasmid pGFP/MP/CP (Table 1). Moreover, mutants AMV1-255, AMV $248-256$, AMV $\Delta 242-256$, BMV1255, and B255:A44, which showed cell-to-cell movement in the context of the pGFP/MP/CP plasmid, showed wild-type or near wild-type levels of accumulation in inoculated leaves (Fig. 5a and b). Because the MPs of mutants AMV1255 and BMV1-255 do not contain the C-terminal 40 amino acids of AMV MP, they are not recognized by the antiserum (Fig. 5d, lanes 3 and 6), although MPs expressed by the other mutants are recognized by the antiserum and migrate at the expected positions on the blot (Fig. 5d, lanes 4, 5, and 7). Mutants AMV1-255, AMV $\Delta 248-256$, and AMV $\Delta 242-$ 256 accumulated in systemically infected leaves of P12 plants, although accumulation of mutant AMV1-255 was somewhat reduced (Fig. 5c, lanes 3, 4, and 5, and Table 1). Analysis of PCR fragments amplified from these mutants confirmed that the mutations were retained in the progeny accumulating in the systemic leaves. No systemic infection was observed with mutants BMV1-255 or B255:A44 (Fig. $5 \mathrm{c}$ and e, lanes 6 and 7).

\section{DISCUSSION}

So far, the use of GFP in the analysis of the mechanism of cell-to-cell movement of viruses from the family Bromoviridae has been limited largely to the transient expression of MP:GFP fusion proteins in plants or protoplasts or the expression of such fusion proteins from the viral genome in protoplasts. CMV engineered to express GFP in place of the MP or $\mathrm{CP}$ as fusions to the $\mathrm{N}$ or $\mathrm{C}$ terminus of MP or from a separate reading frame as part of a tricistronic RNA 3 was able to infect only one to three cells per infection site when inoculated to plants (Canto et al. 1997). Cowpea chlorotic mottle virus (CCMV) was able to produce infection foci of approximately 50 cells when the CP gene in RNA 3 was replaced by the GFP gene, but the absence of CP in this infection significantly affected the phenotype of MP mutants (Osman et al. 1999). The tricistronic AMV transcript of plasmid $\mathrm{pGFP} / \mathrm{MP} / \mathrm{CP}$ used in the present study made it possible to monitor cell-to-cell movement by GFP fluorescence of AMV with a mutated MP and wild-type $\mathrm{CP}$ or with a wild-type MP and mutant $\mathrm{CP}$.

The deletion of 14 or 21 amino acids from the $\mathrm{C}$ terminus of the AMV CP interfered with the formation of detectable virus particles in plants or protoplasts (Tenllado and Bol 2000), yet appeared to have little effect on the cell-to-cell movement of AMV (Fig. 2). This indicates that AMV could move as a viral RNA-protein complex, possibly containing $\mathrm{MP}$ and CP. The finding that tubular structures protruding from AMV-infected protoplasts appeared to be filled with virus particles (Kasteel et al. 1997), however, suggests that virions also can be transported from cell to cell. We observed that a GFP:CP fusion protein entered the tubules on the protoplast surface (Fig. 1f3). This fusion protein is unable to encapsidate viral RNA into stable virions (SánchezNavarro et al. 2001). Possibly the GFP:CP fusion protein 
binds to high-affinity binding sites for $\mathrm{CP}$ at the $3^{\prime}$ terminus of AMV RNA 3 (Bol 1999) and enters the tubules as an RNA-CP complex. Similar to an MP:GFP fusion protein, GFP:CP accumulated in fluorescent spots in the walls between infected cells and in fluorescent rods that traversed the cell wall at the site of these fluorescent spots (Fig. 1f1 and f2). Cell-to-cell transport as a complex of viral RNA, $\mathrm{MP}$, and CP rather than transport of virus particles has been proposed for CMV (Blackman et al. 1998) and potexviruses (Lough et al. 2000).

Within the family Bromoviridae, tubular structures have been observed in plants infected with TSV (Martelli and Russo 1985) and OLV-2 (Grieco et al. 1999). The ability of CMV MP to generate tubules in protoplasts did not correlate with the presence of tubular structures in infected leaf tissue (Blackman et al. 1998). A CMV MP mutant that could spread systemically in tobacco encoded a MP that was unable to form tubules in protoplasts when fused to GFP, thus the requirement of tubule formation for cell-to-cell movement of the

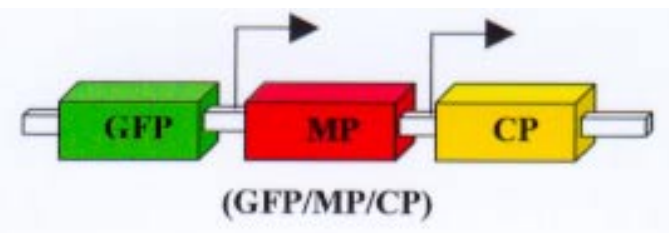

\section{P12 plants}
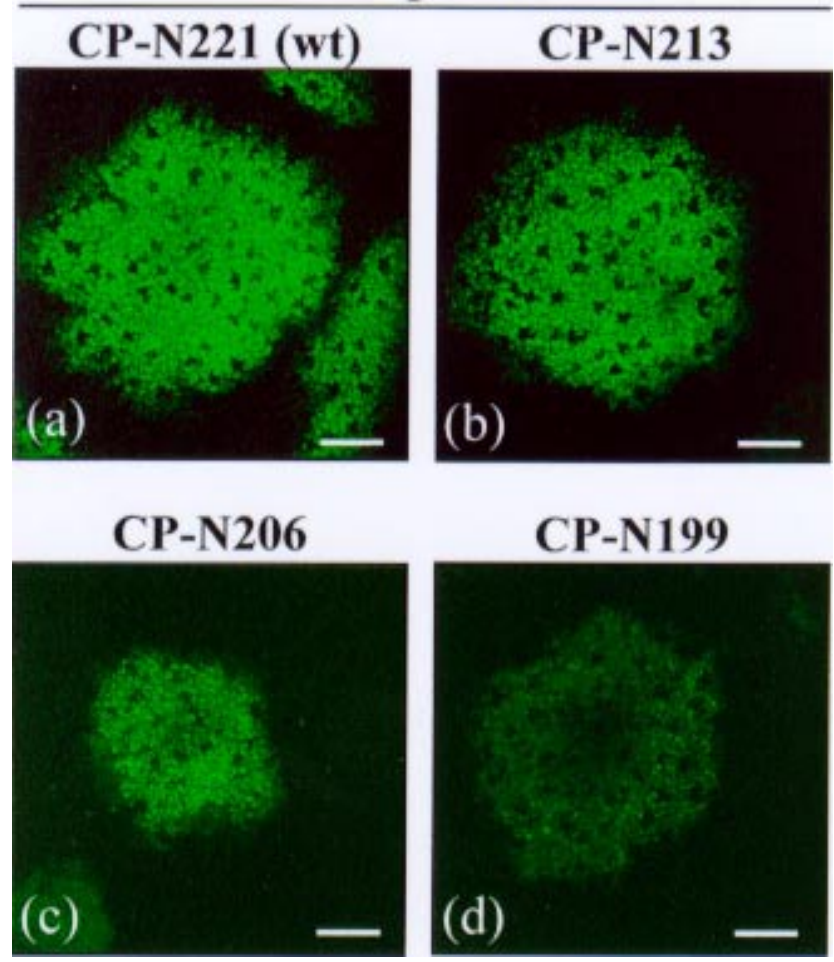

Fig. 2. Detection of infection foci in $\mathrm{P} 12$ plants inoculated with transcripts of plasmid pGFP/MP/CP carrying different coat protein $(\mathrm{CP})$ mutants. P12 plants were inoculated with transcripts of pGFP/MP/CP (a) or the CP mutants pGFP/MP/CP-N213 (b), pGFP/MP/CP-N206 (c), or pGFP/MP/CP-N199 (d). At 3 days after infection, fluorescence was monitored with a confocal laser scanning microscope. Transcript $\mathrm{GFP} / \mathrm{MP} / \mathrm{CP}$ is represented schematically. Bar $=150 \mu \mathrm{m}$. virus was questioned (Canto and Palukaitis 1999). Tubule formation by the nonfused mutant MP was not investigated.

In our studies, all AMV MP mutants that showed cell-tocell movement in plants were able to generate tubules in protoplasts. Additionally, all AMV MP mutants that were defective in tubule formation in protoplasts did not move in plants (Table 1). This is consistent with a role of tubule formation in

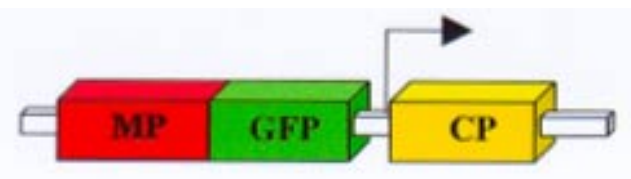

\section{P12 protoplasts}
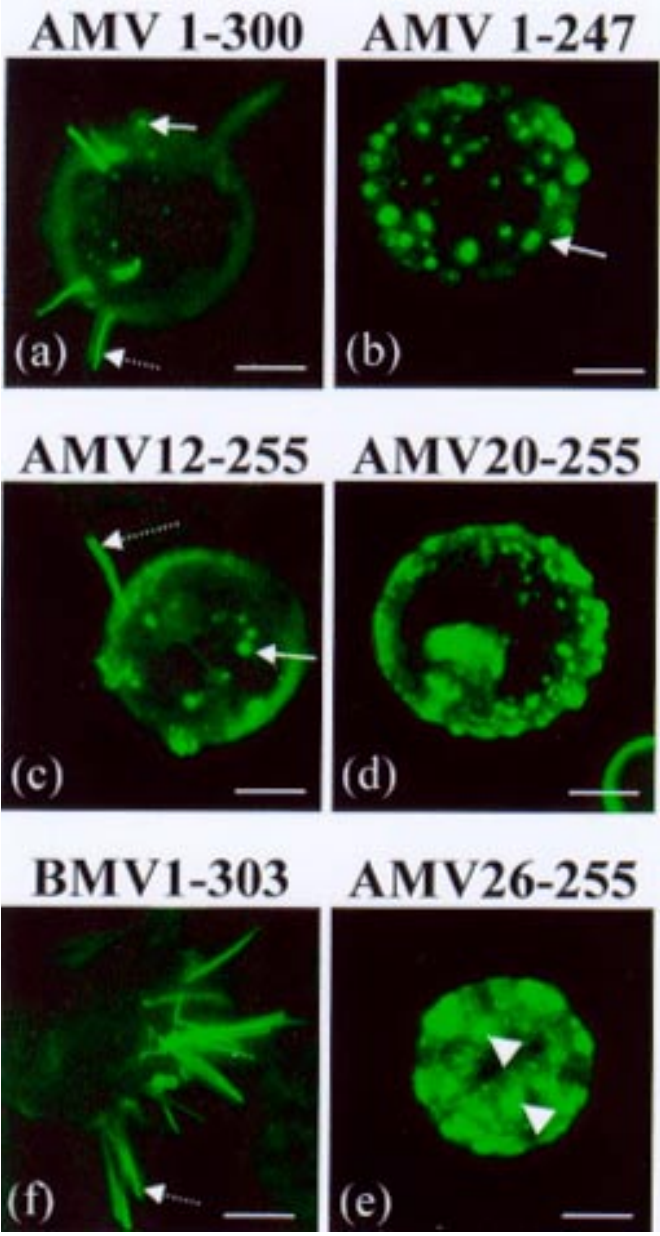

Fig. 3. Fluorescence observed in P12 protoplasts inoculated with transcripts from derivatives of plasmid pMP:GFP/CP expressing mutant movement protein (MP):green fluorescent protein (GFP) fusion proteins. P12 protoplasts were inoculated with transcripts of pA1-300:GFP/CP (a), pA1-247:GFP/CP (b), pA12-255:GFP/CP (c), pA20-255:GFP/CP (d), pB1-303:GFP/CP (e), or pA26-255:GFP/CP (f). Numbers represent the MP amino acid sequences of Alfalfa mosaic virus (AMV) (lane A) or Brome mosaic virus (BMV) (lane B) fused to GFP. The fluorescence was monitored $16 \mathrm{~h}$ after inoculation with a confocal laser scanning microscope. Arrows with solid lines, with broken lines, and arrowheads indicate fluorescent spots, tubular structures, and intracellular aggregates, respectively. Transcript MP:GFP/CP is represented schematically. Bar = $10 \mu \mathrm{m}$. 
cell-to-cell movement of the virus, although no clear correlation between the efficiency of tubule formation in protoplasts and cell-to-cell movement in plants of MP mutants was observed. For instance, the MP:GFP fusion protein of mutant $\Delta 242-256$ induced tubule formation only in $4.6 \%$ of the in-

Table 1. Functional analysis of Alfalfa mosaic virus (AMV) and Brome mosaic virus (BMV) movement proteins

\begin{tabular}{|c|c|c|c|}
\hline $\begin{array}{l}\text { Movement } \\
\text { protein mutant }\end{array}$ & $\begin{array}{c}\text { Tubule } \\
\text { formation }(\%)^{\mathrm{a}}\end{array}$ & $\begin{array}{l}\text { Cell-to-cell } \\
\text { movement }^{b}\end{array}$ & $\begin{array}{c}\text { Systemic } \\
\text { movement }^{\mathrm{c}}\end{array}$ \\
\hline \multicolumn{4}{|l|}{ AMV } \\
\hline (Wild type) $1-300$ & 74.6 & +++ & +++ \\
\hline $1-274$ & 80.6 & - & - \\
\hline $1-267$ & 76.6 & $\mathrm{ND}^{\mathrm{d}}$ & ND \\
\hline $1-260$ & 58 & ND & ND \\
\hline $1-255$ & 60 & ++ & ++ \\
\hline $1-247$ & 0.5 & - & - \\
\hline $1-247+\mathrm{MP}$ & 28 & ND & ND \\
\hline $1-241$ & 0 & ND & ND \\
\hline $1-241+\mathrm{MP}$ & 0 & ND & ND \\
\hline $12-255$ & 9.3 & - & - \\
\hline $20-255$ & 0 & - & - \\
\hline $26-255$ & 0 & - & - \\
\hline$\Delta 248-256$ & 26.6 & +++ & +++ \\
\hline$\Delta 242-256$ & 4.6 & +++ & +++ \\
\hline \multicolumn{4}{|l|}{ BMV } \\
\hline (Wild type) 1-303 & 4 & - & - \\
\hline $1-260$ & 4 & ND & ND \\
\hline $1-255$ & 12 & + & - \\
\hline $1-248$ & 0 & - & - \\
\hline $1-248+\mathrm{MP}$ & 0 & ND & ND \\
\hline $1-240$ & 0 & ND & ND \\
\hline \multicolumn{4}{|l|}{ BMV:AMV } \\
\hline B255:A44 & 13.3 & +++ & - \\
\hline B248:A44 & 0 & - & - \\
\hline \multicolumn{4}{|l|}{ AMV:GFP } \\
\hline A255:G44 & ND & - & - \\
\hline A247:G44 & ND & - & - \\
\hline
\end{tabular}

${ }^{a}$ Movement proteins (MPs) of mutants AMV1-247+MP, AMV1241+MP, and BMV1-248+MP were expressed as MP:green fluorescent protein (GFP) fusions from transcripts of derivatives of plasmid pMP:GFP/MP/CP. MPs of all other mutants were expressed from transcripts of derivatives of plasmid pMP:GFP/CP. For each mutant, the percentage of infected protoplasts that showed tubule formation was averaged from two independent experiments. In each experiment, 150 infected protoplasts were analyzed. Infection of protoplasts was measured by GFP expression. Approximately 40 to $50 \%$ of the protoplasts were infected in each experiment.

b MP was expressed from transcripts of derivatives of plasmid pGFP/MP/CP. +, Low level of cell-to-cell movement was observed at 3 days post infection (dpi) with a mutant in which the C-terminal 48 amino acids of the BMV MP were deleted (mutant BMV1-255). -, Deletion of the C-terminal 26 amino acids (AMV1-274), which resulted in an infection that was limited to single cells. ++, Deletion of the C-terminal 45 amino acids of the MP (AMV1-255), which resulted in the induction of foci at 3 dpi that were significantly smaller. +++, Infection foci induced at 3 dpi by the transcript with wild-type AMV MP.

c The MP was expressed from transcripts of derivatives of plasmid pMP/CP. +, Low level of cell-to-cell movement was observed at 3 dpi with a mutant in which the C-terminal 48 amino acids of the BMV MP were deleted (mutant BMV1-255). -, Deletion of the C-terminal 26 amino acids (AMV1-274), which resulted in an infection that was limited to single cells. ++, Deletion of the C-terminal 45 amino acids of the MP (AMV1-255), which resulted in the induction of foci at 3 dpi that were significantly smaller. +++ , Infection foci induced at $3 \mathrm{dpi}$ by the transcript with wild-type AMV MP.

${ }^{\mathrm{d}} \mathrm{ND}$, Not determined.

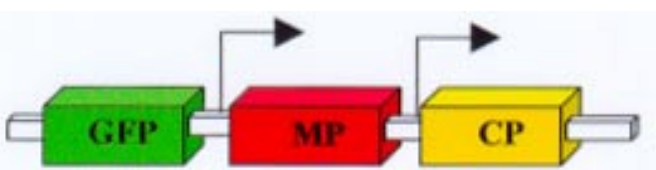

\section{P12 plants}
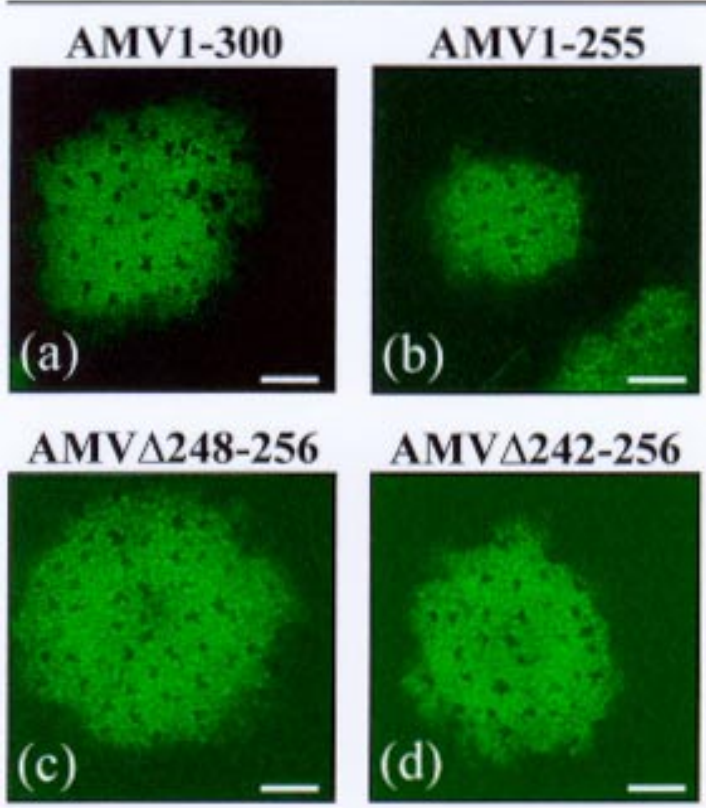

BMV1-254

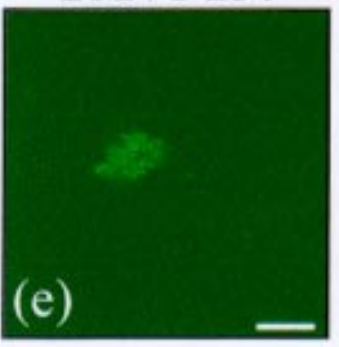

B254:A 43

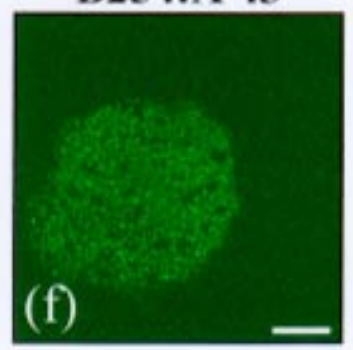

AMV1-247

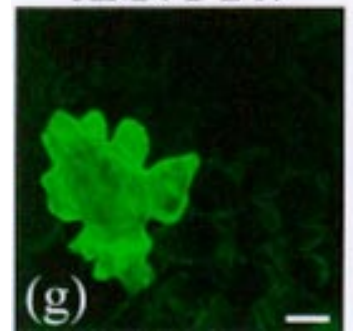

B248:A 43

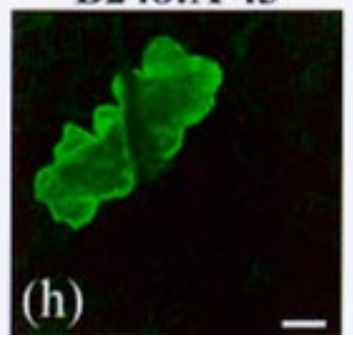

Fig. 4. Fluorescence observed in leaves of P12 plants inoculated with transcripts from derivatives of plasmid pGFP/MP/CP expressing mutant movement protein (MP) genes. P12 plants were inoculated with transcripts of pGFP/MP/CP (a) and its derivatives expressing the MP mutants AMV1-255 (b), AMV $248-256$ (c), AMV $242-256$ (d), BMV1255 (e), B255:A44 (f), AMV1-247 (g), and B248:A44 (h). Fluorescence was monitored 3 days after infection with a confocal laser scanning microscope. Transcript GFP/MP/CP is represented schematically. Bar = $150(\mathbf{a}-\mathbf{f})$ or $10 \mu \mathrm{m}(\mathbf{g}$ and $\mathbf{h})$. 
fected protoplasts, whereas the nonfused MP of this mutant permitted wild-type levels of cell-to-cell movement. These data may reflect differences in the functioning of the fused and nonfused mutant MP. One AMV MP mutant (AMV1-274) showed wild-type levels of tubule formation in protoplasts but was unable to move in plants. Possibly, this mutant is defective in functions other than tubule formation such as in the interaction with viral $\mathrm{CP}$.

The C-terminal 45 amino acids of the AMV MP appears to be dispensable for tubule formation, cell-to-cell movement, and systemic movement. Similar-sized C-terminal deletions (33 to 60 amino acids) did not interfere with the functions of the $30-\mathrm{kDa}$ MPs of TMV, Odontoglossum ringspot virus, CMV, and CCMV (Fenczik et al. 1995; Gafny et al. 1992; Kaplan et al. 1995; Nagano et al. 1997; Osman et al. 1999). The 50-kDa MP of the trichovirus Apple chlorotic leaf spot virus even tolerates a C-terminal deletion of 171 amino acids (Satoh et al. 2000). In the MP mutant AMV1-255, the RNA sequence downstream of the truncated MP gene is not dispensable but is required for subgenomic promoter activity (Van der Vossen et al. 1995). Although the C-terminal 45 amino acids of the AMV MP are not essential for cell-to-cell movement, the three-dimensional structure of this peptide is probably critical to the function of the wild-type MP because partial deletion of this sequence (AMV1-274) or its replacement by a 44 amino acids GFP sequence (A255:G44) interfered with movement. Deletion of the N-terminal 11 amino acids yielded an AMV MP that was fully functional in cell-to-cell movement (Van der Vossen et al. 1995). When the N-terminal 11 amino acids and C-terminal 45 amino acids were deleted (AMV12255), however, the MP was functional in tubule formation but not in cell-to-cell movement. We cannot rule out the possibility that this truncated protein was not stable in plants.

The ability of AMV12-255 to generate tubules was destroyed by a further $\mathrm{N}$-terminal deletion of eight amino acids (AMV20-255), whereas deletion of another six amino acids
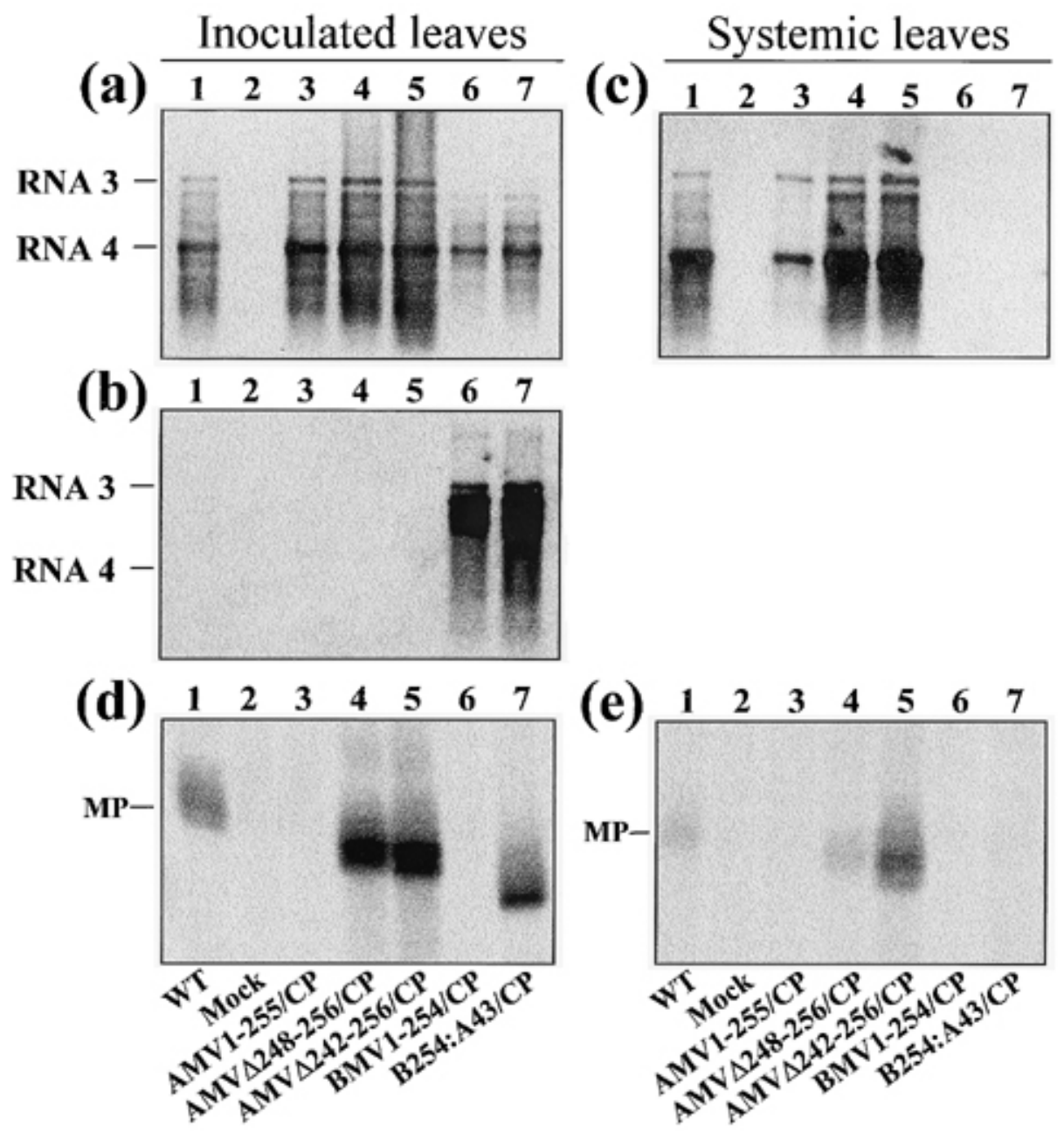

Fig. 5. Northern and Western blot analyses of the accumulation of Alfalfa mosaic virus (AMV) chimeras in P12 plants. a and b, Accumulation of viral RNA in inoculated leaves. c, Accumulation of viral RNA in systemically infected leaves. d and e, Accumulation of wild-type and mutant AMV movement protein (MP) in inoculated (d) and systemic (e) leaves, as detected with an antibody raised to the C-terminal 40 residues of the AMP MP. Blots in a-c were loaded with $100 \mathrm{ng}$ of total RNA, which is equivalent to $0.2 \mathrm{mg}$ of leaf tissue extracted 5 (inoculated leaves) or 12 days (systemic leaves) after infection. Blots were hybridized with probes specific for the AMV coat protein (CP) gene (a and c) or the Brome mosaic virus (BMV) MP gene (b). Plants were inoculated with wild-type AMV RNA 3 (lane 1) or RNA 3 derivatives expressing AMV mutant MPs 1-255 (lane 3), $4248-256$ (lane 4), 4242-256 (lane 5), or BMV mutant MPs 1-255 (lane 6) and B255:A44 (lane 7). Positions of RNA 3, RNA 4, and wild-type AMV MP are indicated on the left. 
affected the targeting of the MP to the protoplast membrane (AMV26-255). The sequence of amino acids 21 to 35 is required for targeting to the cell wall of AMV MP expressed in transgenic plants (Berna 1995; Erny et al. 1992). Although our mutational analysis points to domains of MP involved in tubule formation and movement in plants, the deletions also could affect MP functions by changing the three-dimensional structure of the protein.

The observation that the MP of mutant AMV1-247 became functional in cell-to-cell movement when its $\mathrm{C}$ terminus was extended either with amino acids 248 to 255 (AMV1-255) or 257 to 300 (AMV 248 -256) indicates that the two sequences have similar functions. Possibly, the C-terminal 44 amino acids play a role in determining the specificity of the putative interaction between the MP and CP. The AMV RNA 3 with the MP and CP genes replaced by the corresponding genes of the ilarvirus PNRSV was able to accumulate in tobacco, whereas chimeras that contained either the PNRSV MP or CP could not (Sánchez-Navarro et al. 1997). Similarly, BMV was able to accumulate in Chenopodium quinoa when the MP and $\mathrm{CP}$ genes were replaced by the corresponding CMV genes but not when the MP gene alone was replaced (Nagano et al. 1999). These results point to a specific interaction between the MP and its cognate CP. When the BMV MP gene was replaced by a mutant CMV MP gene that encodes a protein with a C-terminal deletion of 33 amino acids, however, the virus was able to move cell to cell (Nagano et al. 1997). Similar observations have been made for viruses from the genera Tobamovirus (Fenczik et al. 1995) and Potexvirus (Morozov et al. 1999). Additionally, a mutational analysis of the CPMV MP indicated that the $\mathrm{C}$ terminus of this MP interacts with a viral CP (Bertens et al. 2000). The indication that in the family Bromoviridae the $\mathrm{C}$ terminus of the MP contains a determinant for the specificity of the interaction between the MP and CP was further substantiated by our observation that the BMV MP supported AMV cell-to-cell movement only when the C-terminal 48 amino acids were deleted (BMV1-255). This deletion may affect the interaction of the BMV MP with the AMV CP as well as the efficiency of tubule formation by the BMV MP. When the BMV MP sequence of amino acids 1 to 255 was extended with the sequence of the C-terminal 44 amino acids of the AMV MP (B255:A44), the size of the infection foci observed at 3 dpi increased considerably (compare Fig. $4 \mathrm{e}$ and $\mathrm{f}$ ), although there was little effect on tubule formation (Table 1). This could point to a role for this C-terminal sequence in the interaction of the chimeric MP with the AMV CP. When virus accumulation was measured by Northern blot hybridization at $5 \mathrm{dpi}$, the difference in accumulation of mutants BMV1-255 and B255:A44 was less pronounced (Fig. 5). We have not yet compared the time course of the accumulation of the two mutants and the development of infection foci. Interestingly, mutant B255:A44 showed efficient cell-to-cell movement, virus accumulation, and expression of the chimeric MP in inoculated leaves of P12 tobacco plants but no systemic movement was observed (Figs. 4 and 5). After the initial infection of epidermal cells in the inoculated leaf, the virus must move from cell to cell sequentially into mesophyll, bundle sheath, and phloem parenchyma and companion cells to enter the vascular system and to follow the reverse pathway after arrival in the systemic leaves (Carrington et al. 1996). Possibly, mutant B255:A44 is functional in transport from epidermis to mesophyll cells but defective in one or more of the subsequent steps involved in systemic movement. Through the use of immunogold labeling and tissue print techniques, CCMV with the MP gene replaced by that of BMV infected bundle sheath and phloem cells but appeared unable to move through the vascular system of cowpea plants (Fujita et al. 2000).

In summary, our studies with AMV vector RNAs that express the GFP reporter gene support the notion that tubular structures are involved in cell-to-cell movement of AMV and that transport of complexes of viral RNA, MP, and CP rather than transport of virus particles may occur. In addition, our results shed further light on the domains of the AMV MP and $\mathrm{CP}$ involved in local and systemic transport of the virus.

\section{MATERIALS AND METHODS}

\section{Construction of chimeric GFP-AMV cDNA 3 clones.}

DNA manipulation was performed according to Sambrook et al. (1989). The construction of all chimeras was verified by DNA sequence analysis. In the nomenclature of the 63 plasmids used in this study, a slash specifies a sgp sequence in a cDNA construct, whereas a colon indicates an encoded fusion protein. All inserts contain the $5^{\prime}$ and $3^{\prime}$ untranslated regions (UTRs) of AMV RNA 3. The length of truncated MP sequences is indicated. For example, plasmid pGFP/A1-255/CP encodes the $5^{\prime}$ UTR, a duplicated sgp, the AMV MP sequence encoding amino acids 1 to 255, a sgp sequence, the AMV CP gene, and the $3^{\prime}$ UTR.

The plasmids used in Figures 1 and 2 were derived from pGFP/MP/CP (Sánchez-Navarro et al. 2001). To engineer pMP:GFP/MP/CP, the MP sequence was amplified by PCR from pAL3NcoP3 (Van der Vossen et al. 1993) with primers JASN\#22 (5'-GAGAATACAAAAACAAATGCC) and JASN\#77 (5'-CGATGCTAGCATGATCAGGTAATATTTC). The PCR product was inserted upstream of the GFP sequence in pGFP/MP/CP with NheI and NcoI restriction sites. To engineer pGFP:MP/MP/CP, the MP gene was amplified with primers JASN\#28 (5'-ACTCAGATCTCATGGAGAATACAAAAAC) and JASN\#27 (5'-CTAGGAACACTAGGACC), and inserted downstream of the GFP sequence in pGFP/MP/CP with $B g l I I$ and Bstz17I restriction sites. To engineer pCP:GFP/MP/CP, the AMV CP gene was amplified from plasmid pPV84 (Taschner et al. 1994) with primers JASN\#2 (5'-CTTTCAAATACTTCC) and JASN\#34 (5'AAATGCTAGCATGACGATCAAGATCGTC), and the fragment was used to replace the upstream MP sequence in pMP:GFP/MP/CP with NcoI and NheI restriction sites. To engineer $\mathrm{pGFP}: \mathrm{CP} / \mathrm{MP} / \mathrm{CP}$, the $\mathrm{CP}$ gene was amplified from a pPV84 derivative as a NcoI-KpnI fragment and inserted downstream of the GFP in the HindIII site of pGFP/MP/CP. Plasmids pGFP/MP/CP-N213, pGFP/MP/CP-N206, and pGFP/MP/CP-N199 were made by replacing the CP gene in pGFP/MP/CP by CP genes lacking the C-terminal 7, 14, and 21 amino acids of CP, respectively (Tenllado and Bol 2000).

Tubule formation in protoplasts was analyzed with derivatives of pMP:GFP/CP. To engineer pMP:GFP/CP, the fragment containing the sgp-MP-sgp-CP-3' UTR sequence of pMP:GFP/MP/CP (fragment BstZ17I-PstI) was replaced by the RsaI-PstI fragment of pAL3NcoP3 containing the sgp$\mathrm{CP}-3^{\prime}$ UTR sequence. The plasmids carrying the AMV or 
BMV MP mutants fused to the GFP gene were generated by exchanging the AMV MP sequence in pMP:GFP/CP with mutant MP genes that were amplified as NcoI-NheI fragments. C-terminal AMV MP mutants were amplified from plasmid pAL3NcoP3 with sense primer JASN\#22 and antisense primers corresponding to the $3^{\prime}$ end of the truncated MP genes. The BMV wild-type and $3^{\prime}$ truncated MP genes were amplified from the BMV cDNA-3 clone pB3TP7 (Janda et al. 1987) with sense primer JASN\#56 (5'-GCATCCATGGCTAACATAGTTTC) and antisense primers corresponding to the $3^{\prime}$ ends of the truncated genes. By a similar strategy, Nand C-terminal deletions were introduced into the AMV MP. The $5^{\prime}$ terminal truncated MP sequences were preceded by an AUG codon. In pA12-255:GFP/CP, Ser-14 was changed into Ala. In pA26-255:GFP/CP, Leu-28 was changed to Val. Three truncated MP genes were used to replace the upstream MP sequence in pMP:GFP/MP/CP (pA1-247:GFP/MP/CP; pA1241:GFP/MP/CP, and pB1-248:GFP/MP/CP).

Cell-to-cell movement in inoculated leaves was monitored with derivatives of $\mathrm{pGFP} / \mathrm{MP} / \mathrm{CP}$ in which the MP sequence was modified. MP sequences encoding AMV MP, which was C-terminally truncated at amino acids 274,255 , or 247 , and the BMV MP sequences truncated at amino acids 255 or 248 were followed by a TAG stop codon in the context of an AvrII restriction site (CTAG). This restriction site replaced three to six nucleotides of the wild-type MP genes. The AMV sgp sequence (136 nucleotides upstream of the transcription start site) overlaps with the AMV MP gene (Van der Vossen et al. 1995) and was left intact in plasmids that contained BMV MP sequences (pGFP/B1-303/CP, pGFP/B1-255/CP, and pGFP/ B 1-248/CP). To create plasmids pGFP/A $\Delta 248-256 / \mathrm{CP}$, pGFP/A $4242-256 / \mathrm{CP}$, pGFP/B255:A44/CP, and pGFP/B248: A44/CP, the NcoI-NheI fragment of plasmid pGFP/A255/CP was exchanged with the NcoI-NheI fragment of plasmids pA247:GFP/CP, pA241:GFP/CP, pB255:GFP/CP, and pB248: GFP/CP, respectively. In these plasmids, different $\mathrm{N}$-terminal sequences of the AMV or BMV MP are fused to the Cterminal 44 amino acids of the AMV MP. Plasmids pGFP/A255:G44/CP and pGFP/A247:G44/CP were obtained in a two-step procedure. First, the full-length GFP sequence in pA255:GFP/CP and pA247:GFP/CP was replaced by a PCR fragment corresponding to the sequence encoding the $\mathrm{C}$ terminal 44 amino acids of GFP. Subsequently, the A255:G44 and A247:G44 sequences were excised from these derivatives and used to replace the A255 sequence in pGFP/A255/CP.

The mutant MP sequences that were used to replace the MP sequence in $\mathrm{pGFP} / \mathrm{MP} / \mathrm{CP}$ also were used to replace the MP gene in AMV RNA 3 encoded by plasmid pAL3NcoP3 (Table $1)$. These derivatives were used to study long-distance movement of viral RNA. In addition, the MP sequences of plasmids pGFP/A $\Delta 248-256 / \mathrm{CP}, \quad$ pGFP/A $\Delta 242-256 / \mathrm{CP}, \quad \mathrm{pGFP} / \mathrm{B} 255$ : $\mathrm{A} 44 / \mathrm{CP}$, and $\mathrm{pGFP} / \mathrm{B} 248: \mathrm{A} 44 / \mathrm{CP}$ were used to replace the MP sequence in pMP:GFP/CP yielding plasmids pA $\Delta 248$ 256:GFP/CP, pA $\triangle 242-256: G F P / C P, p B 255: A 44: G F P / C P$, and pB248:A44:GFP/CP, respectively. These plasmids were used in studies on tubule formation in protoplasts.

\section{Transient expression of GFP.}

The GFP gene from plasmid pGFP/MP/CP (NcoI-BstZ17I fragment) was cloned behind the Cauliflower mosaic virus $35 \mathrm{~S}$ promoter in the pMOG800 binary vector (Knoester et al.
1998). After transformation of Agrobacterium tumefaciens, a bacterial suspension containing $100 \mathrm{mM}$ acetosyringone was infiltrated into Nicotiana tabacum leaves, essentially as described (Schöb et al. 1997). Three days after infiltration, GFP expression was monitored by confocal laser scanning microscopy.

\section{Inoculation of $\mathrm{P} 12$ protoplasts and plants.}

Plasmids containing wild-type AMV cDNA-3 or GFP derivatives were linearized with $P s t \mathrm{I}$ and transcribed with $\mathrm{T}_{7}$ RNA polymerase, as described previously (Van der Kuyl et al. 1991). Protoplasts were prepared from P12 tobacco plants, according to Van Dun et al. (1988), and $2.5 \times 10^{5}$ protoplasts were inoculated by the polyethylene glycol method (LoeschFries et al. 1985) with $5 \mu \mathrm{l}$ of the transcription mixture. P12 plants were grown and inoculated with RNA transcripts, as described previously (Taschner et al. 1991). Each sample was inoculated on two plants with three half-leaves per plant and $10 \mu \mathrm{l}$ of the transcription mixture per half-leaf as inoculum.

\section{Analysis of inoculated plants.}

Inoculated and systemic leaves were harvested at 5 and 12 dpi, respectively. Total RNA was extracted from $400 \mathrm{mg}$ of infected tissue, as described by Van der Kuyl et al. (1991). Northern blot analyses were performed with approximately $100 \mathrm{ng}$ of total RNA equivalent to $0.2 \mathrm{mg}$ of infected tissue per sample.

\section{Sodium dodecyl sulfate-polyacrylamide gel electrophoresis (SDS-PAGE) and Western blot analysis.}

Leaf tissue $(0.2 \mathrm{~g})$ was triturated with 2 volumes of phosphatidylethanolamine buffer. The homogenate was centrifuged at low speed, the supernatant was mixed with an equal volume of Laemmli loading buffer $2 \times$ (Laemmli 1970), and $7 \mu$ of the mixture was subjected to $12 \%$ SDS-PAGE. Proteins were detected on Western blots (Towbin et al. 1979) with an antiserum against the C-terminal 40 amino acids of the AMV MP and anti-immunoglobulin $\mathrm{G}$ alkaline phosphatase (BoehringerMannheim, Mannheim, German) as a secondary antibody. Bands were visualized with the phosphatase conjugated nitroblue tetrazolium/5-bromo-3-indolyphosphate system, according to the manufacturer's instructions.

\section{Detection of GFP fluorescence in $\mathrm{P12}$ protoplasts and plants.}

GFP expression in planta was analyzed with a MZ 12 stereomicroscope (Leica Microsystems, Wetzlar, German) with a fluorescent light source and a Leica GFP-plus filter set $(\lambda \mathrm{ex}=$ $480 / 40 \mathrm{~nm} ; \lambda$ em $=510 \mathrm{~nm}$ LP barrier filter). GFP expression in protoplasts and plants was analyzed with a MRC 1000 confocal laser scanning microscope (Bio-Rad, Hercules, CA, U.S.A.), with excitation at $488 \mathrm{~nm}$ and emission at $522 \mathrm{~nm}$.

\section{LITERATURE CITED}

Aparicio, F., Sánchez-Navarro, J. A., Olsthoorn, R. C. L., Pallás, V., and Bol, J. F. 2001. Recognition of cis-acting sequences in RNA 3 of prunus necrotic ringspot virus by the replicase of alfalfa mosaic virus. J. Gen. Virol. 82:947-951.

Berna, A. 1995. Involvement of residues within putative $\alpha$ helix motifs in the behavior of the alfalfa and tobacco mosaic virus movement proteins. Phytopathology 85:1441-1448. 
Bertens, P., Wellink, J., Goldbach, R., and Van Kammen, A. 2000. Mutational analysis of the cowpea mosaic virus movement protein. Virology 267:199-208.

Blackman, L. M., Boevink, P., Santa Cruz, S., Palukaitis, P., and Oparka, J. 1998. The movement protein of cucumber mosaic virus traffics into sieve elements in minor veins of Nicotiana clevelandii. Plant Cell 10:525-537.

Bol, J. F. 1999. Alfalfa mosaic virus and ilarviruses: Involvement of coat protein in multiple steps of the replication cycle. J. Gen. Virol. 80:1089-1102.

Canto, T., and Palukaitis, P. 1999. Are tubules generated by the 3a protein necessary for cucumber mosaic virus movement? Mol. PlantMicrobe Interact. 12:985-993.

Canto, T., Prior, D. A. M., Hellwald, K. H., Oparka, K. J., and Palukaitis, P. 1997. Characterization of cucumber mosaic virus, 4: Movement protein and coat protein are both essential for cell-to-cell movement of cucumber mosaic virus. Virology 237:237-248.

Carrington, J. C., Kasschau, K. D., Mahajan, S. K., and Schaad, M. C. 1996. Cell-to-cell and long-distance transport of viruses in plants. Plant Cell 8:1669-1681.

Cheng, C. P., Tzafrir, I., Lockhart, B. E. L., and Olszewski, N. E. 1998. Tubules containing virions are present in plant tissues infected with commelina yellow mottle badnavirus. J. Gen. Virol. 79:925-929.

Citovsky, V., Wong, M. L., Shaw, A. L. Prasad, B. V. V., and Zambryski, P. 1992. Visualization and characterization of tobacco mosaic virus movement protein binding to single-stranded nucleic acids. Plant Cell 4:397-411.

Erny, C., Schoumacher, F., Jung, C., Gagey, M. J., Godefroy, C. T., Stussi-Garaud, C., and Berna, A. 1992. An N-proximal sequence of the alfalfa mosaic virus movement protein is necessary for association with cell walls in transgenic plants. J. Gen. Virol. 73:2115-2119.

Fenczik, C. A., Padgett, H. S., Holt, C. A., Casper, S. J., and Beachy, R. N. 1995. Mutational analysis of the movement protein of odontoglossum ringspot virus to identify a host-range determinant. Mol. PlantMicrobe Interact. 8:666-673.

Fujita, Y., Fujita, M., Mise, K., Kobori, T., Osaki, T., and Furusawa, I. 2000. Bromovirus movement protein conditions for the host specificity of virus movement through the vascular system and affects pathogenicity in cowpea. Mol. Plant-Microbe Interact. 13:1195-1203.

Gafny, R., Lapidot, M., Berna, A., Holt, C. A., Deom, C. M., and Beachy, R. N. 1992. Effects of terminal deletion mutations on function of the movement protein of tobacco mosaic virus. Virology 187:499-507.

Grieco, F., Castellano, M. A., Di Sansebastiano, G. P., Maggipinto, G., Neuhaus, J. M., and Martelli, G. P. 1999. Subcellular localization and in vivo identification of the putative movement protein of olive latent virus 2. J. Gen. Virol. 80:1103-1109.

Heinlein, M., Epel, B. L., Padgett, H. S., and Beachy, R. N. 1995. Interaction of tobamovirus movement proteins with the plant cytoskeleton. Science 270:1983-1985.

Huang, M., and Zhang, L. 1999. Association of the movement protein of alfalfa mosaic virus with the endoplasmic reticulum and its trafficking in epidermal cells of onion bulb scales. Mol. Plant-Microbe Interact. 12:680-690.

Janda, M., French, R., and Ahlquist, P. 1987. High efficiency T7 polymerase synthesis of infectious RNA from cloned brome mosaic virus cDNA and effects of $5^{\prime}$ extensions of transcript infectivity. Virology 158:259-262.

Kaplan, I. B., Shintaku, M. H., Zhang, L., Marsh, L. E., and Palukaitis, P. 1995. Complementation of virus movement in transgenic tobacco expressing cucumber mosaic virus 3a gene. Virology 209:188-199.

Kasteel, D. T. J., Van der Wel, N. N., Jansen, K. A., Goldbach, R. W., and Van Lent, J. W. M. 1997. Tubule-forming capacity of the movement proteins of alfalfa mosaic virus and brome mosaic virus. J. Gen. Virol. 78:2089-2093.

Kim, K.-S., and Lee, K.-W. 1992. Geminivirus-induced macrotubules and their suggested role in cell-to-cell movement. Phytopathology 82:664-669.

Knoester, M., Van Loon, L. C., Van den Heuvel, J., Henning, J., Bol, J. F., and Linthorst, H. J. M. 1998. Ethylene-insensitive tobacco lacks nonhost resistance against soil-borne fungi. Proc. Natl. Acad. Sci. USA 95:1933-1937.

Laemmli, U. K. 1970. Cleavage of structural protein during the assembly of the head of bacteriophage T4. Nature 227:680-685.
Lazarowitz, S. G., and Beachy, R. N. 1999. Viral movement proteins as probes for intracellular and intercellular trafficking in plants. Plant Cell 11:535-548.

Linstead, P. J., Hills, G. J., Plaskitt, K. A., Wilson, I. G., Harker, C. L., and Maule, A. J. 1988. The subcellular location of the gene 1 product of cauliflower mosaic virus is consistent with a function associated with virus spread. J. Gen. Virol. 69:1809-1818.

Loesch-Fries, L. S., Halk, E. L., Nelson, S. E., and Krahn, K. J. 1985. Human leukocyte interferon does not inhibit alfalfa mosaic virus in protoplasts or tobacco tissue. Virology 143:626-629.

Lough, T. J., Netzler, N. E., Emerson, S. J., Sutherland, P., Carr, F., Beck, D. L., Lucas, W. J., and Forster, R. L. S. 2000. Cell-to-cell movement of potexviruses: Evidence for a ribonucleoprotein complex involving the coat protein and first triple gene block protein. Mol. Plant-Microbe Interact. 13:962-974.

Martelli G. P., and Russo M. 1985. Pages 163-205 in: The Plant Viruses R. I. B. Francki, ed. Plenum Press, NY.

McLean, B. G., Zupan, J., and Zambryski, P.C. 1995. Tobacco mosaic virus movement protein associates with the cytoskeleton in tobacco cells. Plant Cell 7:2101-2114.

McLean, B. G., Hempel, F. D., and Zambryski, P. C. 1997. Plant intercellular communication via plasmodesmata. Plant Cell 9:1043-1054.

Melcher, U. 2000. The " $30 \mathrm{~K}$ " superfamily of viral movement proteins. J. Gen. Virol. 81:257-266.

Morozov, S. Y., Solovyev, A. G., Kalinina, N. O., Fedorkin, O. N., Samuilova, O. V., Schiemann, J., and Atabekov, J. G. 1999. Evidence for two nonoverlapping functional domains in the potato virus X $25 \mathrm{~K}$ movement protein. Virology 260:55-63.

Nagano, H., Okuno, T., Mise, K., and Furusawa, I. 1997. Deletion of the C-terminal 33 amino acids of cucumber mosaic virus movement protein enables a chimeric brome mosaic virus to move from cell to cell. J. Virol. 71:2270-2276

Nagano, H., Mise, K., Okuno, T., and Furusawa, I. 1999. The cognate coat protein is required for cell-to-cell movement of a chimeric brome mosaic virus mediated by the cucumber mosaic virus movement protein. Virology 265:226-234.

Osman, F., Schmitz, I., and Rao, A. L. N. 1999. Effect of C-terminal deletions in the movement protein of cowpea chlorotic mottle virus on cell-to-cell and long-distance movement. J. Gen. Virol. 80:1357-1365.

Poirson, A., Turner, A. P., Giovane, C., Berna, A., Roberts, K., and Godefroy-Colburn, T. 1993. Effect of alfalfa mosaic virus movement protein expressed in transgenic plants on the permeability of plasmodesmata. J. Gen. Virol. 74:2459-2461.

Ritzenthaler, C., Schmit, A.-C., Michler, P., Stussi-Garaud, C., and Pinck, L. 1995. Grapevine fanleaf nepovirus P38 putative movement protein is located on tubules in vivo. Mol. Plant-Microbe Interact. 8:379-387.

Sambrook, J., Fritsch, E. F., and Maniatis, T. 1989. Molecular Cloning: A Laboratory Manual, 2nd ed. Cold Spring Harbor Laboratory, Cold Spring Harbor, NY, U.S.A.

Sánchez-Navarro, J. A., and Pallás, V. 1997. Evolutionary relationships in the ilarviruses: Nucleotide sequence of prunus necrotic ringspot RNA 3. Arch. Virol. 142:749-763.

Sánchez-Navarro, J. A., Reusken, C. B. E. M., Bol, J. F., and Pallas, V. 1997. Replication of alfalfa mosaic virus RNA 3 with movement and coat protein genes replaced by corresponding genes of Prunus necrotic ringspot ilarvirus. J. Gen. Virol. 78:3171-3176.

Sánchez-Navarro, J. A., Miglino, R., Ragozzino, A., and Bol, J. F. 2001. Engineering of Alfalfa mosaic virus RNA 3 into an expression vector. Arch. Virol. 146:923-939.

Satoh, H., Matsuda, H., Kawamura, T., Isogai, M., Yoshikawa, N., and Takahashi, T. 2000. Intracellular distribution, cell-to-cell trafficking and tubule inducing activity of the $50 \mathrm{kDa}$ movement protein of apple chlorotic leaf spot virus fused to green fluorescent protein. J. Gen. Virol. 81:2085-2093.

Schöb, H., Kunz, C., and Meins, F. 1997. Silencing of transgenes introduced into leaves by agroinfiltration: A simple, rapid method for investigating sequence requirements for gene silencing. Mol. Gen. Genet. 256:581-585.

Schoumacher, F., Giovane, C., Maira, M., Poirson, A., GodefroyColburn, T., and Berna, A. 1994. Mapping of the RNA-binding domain of the alfalfa mosaic virus movement protein. J. Gen. Virol. 75:3199-3202.

Storms, M. M. H., Kormelink, R., Peters, D., Van Lent, J. W. M., and 
Goldbach, R. W. 1995. The nonstructural NSm protein of tomato spotted wilt virus induces tubular structures in plant and insect cells. Virology 214:485-493.

Taschner, P .E. M., Van der Kuyl, A. C., Neeleman, L., and Bol, J. F. 1991. Replication of an incomplete alfalfa mosaic virus genome in plants transformed with viral replicase genes. Virology 181:445-450.

Taschner, P. E. M., Van Marle, G., Brederode, F. T., Tumer, N., and Bol, J. F. 1994. Plants transformed with a mutant alfalfa mosaic virus genome coat protein are resistant to the mutant but not to wild type virus. Virology 203:269-276.

Tenllado, F., and Bol, J. F. 2000. Genetic dissection of the multiple functions of alfalfa mosaic virus coat protein in viral RNA replication, encapsidation, and movement. Virology 268:29-40.

Towbin, H., Staehelin, T., and Gordon, J. 1979. Electrophoretic transfer of proteins from polyacrylamide gels to nitrocellulose sheets: Procedure and some applications. Proc. Natl. Acad. Sci. USA 76:4350-4354.

Van der Kuyl, A. C., Neeleman, L., and Bol, J. F. 1991. Complementation and recombination between alfalfa mosaic virus RNA 3 mutants in tobacco plants. Virology 183:731-738.

Van der Vossen, E. A., Neeleman, L., and Bol, J. F. 1993. Role of the 5 leader sequence of alfalfa mosaic virus RNA 3 in replication and translation of the viral RNA. Nucleic Acids Res. 21:1361-1367.

Van der Vossen, E. A. G., Neeleman, L., and Bol, J. F. 1994. Early and late functions of alfalfa mosaic virus coat protein can be mutated separately. Virology 202:891-903.

Van der Vossen, E. A. G., Notenboom, T., and Bol, J. F. 1995. Characterization of sequences controlling the synthesis of alfalfa mosaic virus subgenomic RNA in vitro. Virology 212:663-672.

Van Dun, C. M. P., Van Vloten-Doting, L., and Bol, J. F. 1988. Expression of alfalfa mosaic virus cDNA 1 and 2 in transgenic tobacco plants. Virology 48:699-708.

Van Lent, J., Wellink, J., and Goldbach, R. 1990. Evidence for the involvement of the $58 \mathrm{k}$ and $48 \mathrm{k}$ proteins in the intercellular movement of cowpea mosaic virus. J. Gen. Virol. 71:219-233.

Wolf, S., Deom, C. M., Beachy, R. N., and Lucas, W. J. 1989. Movement protein of tobacco mosaic virus modifies plasmodesmatal size exclusion limit. Science 246:377-379.

Zheng, H., Wang, G., and Zhang, L. 1997. Alfalfa mosaic virus movement protein induces tubules in plant protoplasts. Mol. Plant-Microbe Interact. 10:1010-1014. 